\title{
Taking a Look in the Mirror:
}

The Inversion of Middle-Class

Fears of Urban Decay and

the Representation of

Racial Violence in

Bernard Rose's Candyman

\section{Jacob Garrett, Ball State University}

Horror fiction has often utilized urban settings, specifically spaces plagued by urban decay, as tools to inspire fear in the middle- and upper-class readers who devour these stories. Authors and directors exploit these people's anxieties about falling into a lower economic class and their determination to ignore the twisted, horrible history of racial violence and discrimination that contribute to the conditions that people in such neighborhoods would live in. This paper seeks to illustrate how, in the 1992 film Candyman, director Bernard Rose turns these tropes on their heads to terrify his audiences in an entirely different way.
In the American cultural consciousness, the city has always carried with it an element of sinister foreboding. Major metropoles like New York City and Los Angeles have, in recent decades, taken on an aura of fantastical fascination, viewed as places where people from all walks of life can make something of themselves and become the person that they are meant to be. This perception, however, is fairly new compared to the association of both physical and moral decay with the nation's cities, which goes back to the foundation of the United States itself: "Thomas Jefferson, for instance, viewed giant urban centers such as New York as 'cancers' on the body politic and as potential dangers to democracy" (Macek

82). This view has made its way into every facet of American culture through the centuries, and literature is no exception to this rule. Horror literature dating all the way back to H. P. Lovecraft presents a link "between urban decay and 
immigration, and by implication historic preservation and anti-immigrant sentiment" (Evans 109). In thrillers, film noir, and modern horror movies in particular, this association is made even more prominent by the union of these films' prime villains or antagonists with the cities in which these movies take place. In David Fincher's Seven, for example, the unnamed city in which the murders take place is "a thoroughly noxious, menacing place, an allegorical Hell as full of suffering and anguish as the Inferno of Dante on which it appears to have been modeled" (Macek 83). Writer-directors such as Bernard Rose, however, while tapping into this collective societal fear of the inner city, go beyond simply playing off of instinctual white, middle-class anxiety and revulsion. In the 1992 film Candyman, Rose exploits both the white middle-class fear of urban decay and ignorance about the pervasiveness of racial violence in the United States, turning these ideas on their heads and forcing the viewer to reckon with the unacknowledged history that haunts the back of their minds.

In the 1990s, there was no more potent invocation of urban decay, inner-city violence, and the general fear of housing projects in the eyes of the public than the Cabrini-Green Homes development in Chicago. Situated near the Gold Coast neighborhood-which was and still is one of the richest in the United States-Cabrini-Green "stood as the symbol of every troubled housing project-a bogeyman that conjured fears of violence, poverty, and racial antagonism" (Austen). It became especially notorious during the decade leading up to Candyman, during which there were "eleven murders and thirty-seven gun injuries reported in the first two months of 1981," as well as an incident just before the film came out where a young boy was killed by a sniper (Briefel and Ngai 76). High rates of crime, however, were not all of what put this area in the center of the media's focus during this period: "Other public housing developments in the city were larger, poorer and had higher rates of crime. But in the extreme segregation of Chicago, Cabrini-Green... remained that uncommon frontier where whites still crossed paths with poor blacks" (Austen). Since Cabrini-Green stared the Gold Coast in the face, it was impossible for the almost completely white and upper-class population of the Gold Coast to ignore it, as they did with other housing projects in and around Chicago. The entire development was eventually destroyed, with demolition commencing three years after Candyman was released and the last high-rise being torn down in 2011, but that did not stop the endemic poverty that plagued the residents of the development. Even though all the people living in Cabrini-Green were relocated, "the demolitions didn't do away with the poverty and isolation of public housing; these problems were moved elsewhere, becoming less visible and no longer literally owned by the state" (Austen). They were simply put out of sight, which was enough for the people of Chicago and the Gold Coast to 
consider the issue "solved."

The Cabrini-Green that viewers are shown in Candyman seems to be exactly like this stereotype on the outside: all the plant life around the complex is dead; the walls are covered in graffiti ranging from complex murals to unintelligible scribbles, and they are often shown to be crumbling; trash and discarded furniture is scattered everywhere; and any bit of exposed metal exhibits flecks of rust. Many shots of the complex also show the high-rises of downtown Chicago, particularly the former Sears Tower, looming over the neighborhood in the distance; the viewer knows that they are relatively close, but every shot that includes these buildings makes them seem impossibly far away. The housing project is visually separated from the famous skyline that so many Americans associate with Chicago, and the sheer height of these buildings compared to the apartment complexes of Cabrini-Green make it seem as though the rest of the city is looking down upon the people that live there.

It is this pervasive disdain for Cabrini-Green and its residents among the people of Chicago and the United States at large that sets the stage for Candyman. While conducting a graduate thesis on urban legends, Helen Lyle, a well-to-do white woman and the wife of a professor at the University of Illinois in Chicago, and her best friend Bernadette Walsh, a black woman of similar economic status, decide to pursue the story of Candyman, a ghostly figure who appears and murders you with a hook if you say his name five times in a mirror. When a janitor at the university tells Helen that her cousin's friend was murdered by Candyman at the Cabrini-Green development, Helen decides to investigate further, taking Bernadette with her. While Helen's determination to get to the bottom of the story outweighs any fear she might have about visiting this part of town, Bernadette is not so unwary: she packs mace and a taser in her purse, warns Helen that their conservative dress will make them look like cops to the residents, and briefly implores her friend to abandon the trip altogether. The visuals during this part of the movie seem to confirm her worries: the camera follows their car on the way to Cabrini-Green from a birds-eye view, making them look tiny and fragile on the very highway that keeps Cabrini-Green cordoned off from the rest of Chicago. Even though Bernadette finally agrees to come in when they arrive, she is constantly on edge.

She appears to be more at ease when invited into the apartment of a single mother named Anne-Marie, who assures the two women that "we ain't all like them assholes downstairs" (Candyman 26:27-26:30), referring to a group of young men that harassed Bernadette and Helen, but this rapprochement comes only after Anne-Marie provides a jump scare by showing up with her chained rottweiler and interrogating them. Bernadette sees Anne-Marie as a threat until she 
invites them into her apartment, where her child is also present, and tells them all the ways in which the people that tend to visit Cabrini-Green only do so to disparage the neighborhood and its residents. Even though she is willing to recognize that she was wrong about this person in particular, Bernadette cannot shake off her ingrained class prejudices. Bernadette is self-aware enough to point out the important fact that they will not be seen as benevolent intellectuals while they are in the projects, since their "vestmental code could be received suspiciously by a different community of readers, as a marker of intrusive authority rather than anonymity," but this first visit to Cabrini-Green also puts her own biases on full display (Briefel and Ngai 78).

Helen's character, however, acts against Bernadette's class prejudice, downplaying her friend's fears about the people living there and saying, when she sees her friend's mace and taser, "What's with the arsenal, Bernadette? We're only going eight blocks" (Candyman 16:59-17:01). Helen doesn't buy the idea that there is a significant difference between her circle of friends and the people at Cabrini-Green, telling Bernadette that her upscale condo used to be part of a housing project: "Once it was finished, the city soon realized that there was no barrier between here and the Gold Coast....So they made some minor alterations. They covered the cinder block in plaster, and they sold the lot off as condos" (13:41-13:58). She hammers home the truth of this fact by going to her bathroom mirror, pulling it out, and pushing the slab of plastic behind it out of the wall, revealing that the only thing separating her apartment from the one next door is the thin protection of two mirrors that come right out if any force is applied to them. This detail is revisited when Helen and Bernadette are exploring Cabrini-Green, where Helen crawls through a hole where a mirror used to be to find a shrine to Candyman hidden in a rotting apartment. Helen is willing to admit that she is not so far from the people of Cabrini-Green as some might like to think; without fear, she acknowledges the permeability of class distinctions, which many middle- and upper-class Americans might like to consider as more rigid. Unlike Bernadette, she is perfectly at ease walking through the projects and crawling through walls to enter vacant apartments that Bernadette warns her might be occupied by drug dealers. In a way, she is at home there.

The fact that Helen accepts Cabrini-Green, lives in an extremely well-furnished apartment that was once just like it, and willingly crosses between the two with seemingly no concern for her own safety deliberately plays on traditional middle- and upper-middle-class fears about economic divisions and the "dangers" of urban squalor to those who have a higher socioeconomic status. In his discussion of so-called "yuppie horror," film critic Barry Keith Grant says, "In an economy characterized by economic polarization and spreading poverty, these scenes of crossing into the nether world of urban decay exude the Manichaean, middle-class paranoia...that once 
you leave a bourgeois life, you're immediately prey to crime, madness, squalor, and poverty" (5). These are exactly the fears that Rose interacts with in the film, deliberately making the viewer confront these worries within themselves. He forces them to realize that the projects aren't one dark, terrifying, unified organism of terror, but are filled with diverse groups of people who have fallen on hard times, shoved to the side by the American public as murderers, drug dealers, and rapists without grounds. Such criminals were of course present in the projects, but they were a minority who were looked down upon by their neighbors rather than accepted as the norm, just like everywhere else. The terror of the middle-class general public of possibly falling victim to the same processes that doomed the projects haunts them and makes them unable to see the truth. Furthermore, as funds for housing projects across the country were slashed during the tenures of the Reagan and Bush administrations and more and more people were forced to relocate, horror films in the years leading up to the release of Candyman embodied yet another terror affecting the white middle class: "an irrational fear of infiltration from those evicted from subsidized housing," exemplified by the "insistence [of pre-Candyman slasher films] on preserving the intactness of [their] middle-class control group[s] of victims" (Briefel and Ngai 74).

The fact that Helen is white also forces both the characters and the viewer to reckon with the history of racial oppression and violence that is attached to the legend of Candyman and the projects themselves. Candyman, according to legend, was originally Daniel Robitaille, the son of a former slave. His father became rich, and Robitaille himself became a skilled and highly respected portrait painter. When he fell in love with and impregnated the daughter of a wealthy white landowner, however, he was lynched in gruesome fashion. The hand he painted with was cut off with a rusty saw, his naked body was smeared with honey, and an angry swarm of bees was released upon him, leading to his death from blood loss and bee stings. Lynching was one of the most brutal, hate-filled, and pervasive types of racial violence after the Civil War, and this instance in particular is extremely horrifying and spiteful. Rather than hanging and burning him, as was typical of a lynching, they took the time to eliminate his connection to white society (his painting hand) and to kill him with a symbol of the very sweetness that appealed to his lover in the first place (the honey).

The extreme malice that the people of Reconstruction-era Chicago showed toward Robitaille likely stemmed from the contemporary fear among middle- and upper-class white Americans of interracial couples and biracial children, whom they saw as "impure" and as a "corruption" of whiteness. It was not primarily the fact that Robitaille was well-to-do that sent these people after him (although his wealth was likely a factor), but that he and his lover would have created a 
biracial child who, to their even greater fear, may have passed for white, that caused them to react in so visceral and sadistic a fashion. This is what sets this lynching apart from many others, aside from the physical details of the incident; it was not just the punishment of a black man for having sex with a white woman, but for conceiving a child with said white woman who could completely defy and eliminate the traditional idea that the white middle and upper classes were "pure."

It is in Cabrini-Green that this legacy of horrific violence, prejudice, and American anxieties about racial divides are on full display. In her essay about the role of the urban gothic in slasher films, author Stacey Abbot links Cabrini-Green to traditional conceptions of the "Terrible Place" in urban gothic, which can be described as needing "a concentration of memories and historical associations" which "would [ideally] be expressed in an extant architectural or topographical heritage, as these areas provide for ghostly presences of imagined/projected meanings" (70). The fact that Cabrini-Green was built upon the same site as that of Robitaille's lynching and exhibits the systematic economic oppression and unofficial segregation of African Americans in the United States-Bernadette explicitly describes it as a ghetto at one point-means that the housing project fits into this description perfectly. We are given inklings of the complex racial dynamics at play there during the first half of the movie, such as when Anne-Marie says, "You know, whites don't ever come here, except to cause us a problem" (Candyman 25:48-25:50). Helen, unbeknownst to herself, has become "a perpetrator of White colonial aggression. Although several Black women characters advise her against intruding on community spaces and disrespecting sites of death, she pushes forward with her research agenda in hopes of publication" (Kee 52). She is well-intentioned in her investigation and does not mean to cause any trouble or harm, but she is still participating in the cultural norms that have oppressed Cabrini-Green by treating it merely as a space in which to freely conduct her research, rather than as a place filled with real people who are living in very real homes (52). The racial dynamics in the film come to a head with the appearance of Candyman, who in fact takes two forms.

The first form that we see is the leader of a gang, the Overlords, who calls himself Candyman and carries a hook around with him. This first version of Candyman has taken on the persona of the legendary ghost to inspire fear in the residents of Cabrini-Green and to create a near-mythical status for himself within the neighborhood. This Candyman is almost a specter unto himself, invisible until Helen visits the project alone to interview Anne-Marie a second time. When she arrives, she meets a young boy called Jake who tells her that he can lead her to Candyman. He takes her to a public restroom outside the building where he says Candyman can be found before telling her a story about a child being horribly mutilated by Candyman in that very bathroom. 
When Helen enters, she checks all of the stalls and, in the last one, finds a colony of bees nesting inside the toilet bowl. She slams it shut and turns to leave when a young man walks in, who, as four other men follow him, pulls a hook from behind his back. When she tries to leave, they restrain her and he says, "I hear you're looking for Candyman, bitch. Well, you found him" (Candyman 38:57-39:01), before hitting her over the head with the hook.

Helen is in genuine danger during this scene, and everything about the environment in which it takes place heightens this feeling. There is graffiti and grime all over the walls, and all the toilets, excepting the one filled with bees, are smashed to pieces. Spread over the wall and door of the stall with the bee toilet, in what appears to be human feces, is the phrase "sweets to the sweet," which appeared near the aforementioned shrine to Candyman and marked the locations where Candyman murdered people. The scene also seems to suggest the potential for sexual assault; the bathroom is a space of extreme vulnerability, and the disgusting nature of this one has already set the viewer on edge. This sense of unease heightens when one of the Overlords restrains her and their leader gets very close to her, grabbing her neck before hitting her with the hook. It is a nightmare scenario for a white middle-class intellectual woman in this situation, and, while they leave her in the bathroom after hitting her in the head a few more times (enough to leave a pool of blood beneath her), Rose deliberately constructed this scene to play off of every stereotype that people had of Cabrini-Green in this time period and that the white middle and upper classes would have had of areas suffering from urban decay in general. This fact is only compounded by multiple characters expressing their fear for Helen's safety and her good fortune at being alive after this incident.

To Helen, the mystique and legend surrounding the gang leader iteration of Candyman falls apart after this incident. He is quickly arrested, and when Helen sees Jake at the police station, she assures him, against his protestations that Candyman will come for him, that "Candyman" was never real: it was only a bad man wearing the name like a cloak. At this point in the film, the gang leader can be seen as emblematic of the perception that most Americans had of Cabrini-Green: violent, coarse, and mired in crime, inspiring fear and whispers. He doesn't even have a name; his persona begins and ends with his role as the head of the Overlords and someone who adopts the persona of Candyman. Helen and the police think that, by rooting him out and bringing him into custody, they have solved the mystery of Candyman and put a stop to a major blight on the area; however, it is soon after this incident that the actual ghost of Candyman appears to Helen in a parking garage, proving them dead wrong.

When Helen enters the garage, she sees a dark figure standing at the other end of the 
building; he is covered by a long, flowing black coat, and his right hand is replaced by an enormous, bloody hook. Helen tries to leave, but she is hypnotized, unable to break free from the spell of the true and undeniable Candyman, who proclaims to her, "I am the writing on the wall, the whisper in the classroom. Without these things, I am nothing. So now, I must shed innocent blood. Come with me" (53:29-53:12). This language is different from the more direct language of the gang leader and the tag associated with him, "sweets to the sweet," immediately signifying the divide between himself and who Helen thought to be Candyman in the first place.

Helen faints, only to wake up on the floor of a bathroom as someone wails nearby. She is covered by a long black coat and pulls it back to reveal a huge pool of blood on her stomach and the floor around her. When she opens the door, she discovers the severed head of a rottweiler lying on the floor of a hallway, a meat cleaver lying beside it. She takes the knife and emerges to find Anne-Marie, standing over her son's empty, gore-soaked crib, screams of grief and sorrow tearing from her lungs. When Anne-Marie sees Helen standing there holding the still-bloody knife, she lunges, demanding that Helen tell her where her baby is as she tackles her and slams her head into the floor. Helen manages to get the upper hand, but that's when the police burst in, finding a white woman kneeling over a black woman holding a meat cleaver, the white woman's shirt and the apartment around them already covered in blood, and an empty crib so saturated with crimson that it seems no child that lay within could still be alive.

This is the moment that the racial dynamics that Rose has been hinting at finally burst onto the screen. While we assume that Helen had nothing but the best of intentions when talking to Anne-Marie earlier in the film, the fact that she has been caught in this situation seems to confirm Anne-Marie's prior statement that white people only come to Cabrini-Green to cause trouble. We would like to think that Helen is innocent in all this, framed for the murder by a vengeful ghost, but it is impossible for the viewer to be sure at this point that Helen did not kill the dog and commit infanticide. Furthermore, when Helen is brought to the police station where she originally reported the gang leader and is asked to take off her clothes, this act covers the entirety of her upper body in blood, a visual which tacitly compounds the fact that she might be guilty. The veracity of her own account is also thrown into question by the fact that she so recently sustained a head trauma severe enough to leave a sizable pool of blood on the ground, meaning that her vision in the garage could have been a hallucination (Kee 53).

The ghostly Candyman, as opposed to the gang leader, embodies not society's perceptions of the housing projects, but the horrible history of racial violence that has soaked the pages of the history in the United States. Helen and the police were perfectly willing to accept the reality of the 
fake Candyman, but it isn't until the real Candyman stares her in the face that Helen admits that he exists and still has the power to hurt people in the modern world. His appearance also puts the death of a child on the hands of a white woman in both a mirror image of his own gruesome end (since the blood that has soaked Helen's sweater when she wakes up only covers her stomach, an apparent callback to the fact that Candyman was murdered for impregnating a white woman) and in a resurrection of that very event at the site upon which his death occurred. In fact, "Helen's subjection by the history she seeks is signaled throughout Candyman by the repetition of mirror images. On a basic psychoanalytic level, staring into a mirror to summon Candyman (who then will burst through the mirror and wreak havoc) indicates that Candyman dwells in the desiring subject's unconscious," and this moment is where Rose masterfully uses Helen's being framed to scare the white middle class (Wyrick 95).

Anyone who grows up in the United States is aware of the brutal oppression and pain that people of color faced throughout the nation's history; however, there are those who would like to believe that this inequality is all in the past, part of a bygone era that has no bearing on today's reality, relegating it to what Candyman calls himself: a whisper in the classroom. The ghost of Daniel Robitaille, functioning as a stand-in for that very history that haunts the American consciousness, forces the viewer to reckon with the fact that it is not so far behind them as they might like to think and that it still has the power to hurt people in the modern day. For all her education and good will, Helen (and, by extension, the white middle-class viewer prior to this point) has been unable to see the power that racism and racial violence hold over the American consciousness because of her white privilege until she is literally paralyzed from fear of this power. Then, just after recognizing it as real and tangible, she opens her eyes again on a world turned on its head and drenched in blood and despair. When Candyman was just an idea to her, Anne-Marie's apartment seemed almost untouched by the violence that permeated that spot a century before; after he became real to her, Helen herself became mired in the very history of death and gore to which she had, until now, been blissfully blind. This idea is compounded by the fact that the characters treat Candyman as just another horror-themed urban legend during the first half of the movie, thinking him similar to Bloody Mary. The Bloody Mary legend has been normalized in Western culture, and even though it is a terrifying concept, nobody actually thinks of it as real or dangerous because, as children, everybody is told that it is just a story. Similarly, while the history of racial injustice in the United States is extremely horrific and deplorable, white people frequently talk of it in the modern age as though it is just a story, rather than as a force that can genuinely harm people. 
The importance of bathrooms in the film is further evidence of this interpretation of Candyman. Bathrooms tend to have two different associations: that of filth and unpleasant bodily functions and that of relaxation, peace, and cleanliness. The fact that Candyman appears to someone when they look in a mirror tacitly associates him with the act that would take place most often when someone is looking in a mirror: washing hands. The washing of hands symbolically means the elimination of one's guilt about something they witnessed or took part in, and Candyman's modus operandi means that this act is no longer enough. The people summoning him as a game in their bathrooms can no longer just wash their hands of the history that he represents and leave it behind when they lose interest; they have to deal with the consequences. The two bathrooms at Cabrini-Green, in turn, show how this violence and dirty national history cannot be avoided there. The bathroom that Helen awakens in is splattered with blood and is never shown to be cleaned up, and the bathroom in which she is assaulted is covered with grime and literal feces, and its sinks and toilets are all smashed to pieces. No relief or cleanliness can be found in these bathrooms; the horrid, reeking, poisonous filth that covers those bathrooms, just like the horrid, reeking, poisonous murder that infected that property, can never be washed away.

The murder of Candyman's second victim, Bernadette, cements this line of thinking. When Candyman appears to Helen this time, it is first by shoving his bloody hook through the mirror at her, both compounding the emphasis on mirror images and reminding the viewer of Helen's earlier story about the apartment being a former housing project. He then traps her in her kitchen, where she grabs a knife, and paralyzes her once again. This time, however, he is interrupted by Bernadette, who came to check up on Helen. Bernadette enters only to have the door swing shut behind her. When she turns around, she sees Candyman standing there, slowly raising his hook.

This moment is significant because Bernadette is the only character aside from Helen herself who sees Candyman at any point during the movie. While Candyman claims another victim later in the film, this third victim doesn't see him coming at all, as Candyman kills him from behind. Everyone else is unable to see him, even if Helen claims he is right in the room with them, leading them to believe her insane. Bernadette, however, sees him immediately. As a black woman, Bernadette would have been far more aware of the ways that the racial violence and hatred that has saturated American history still affects the modern world than her white associates and friends. She is therefore able to see Candyman the second that she encounters him, almost seeming to recognize him for who he is in the few seconds before he kills her. After she has been murdered, Helen's husband Trevor returns to find Helen unconscious in the kitchen, holding a knife and covered in blood, with Bernadette's eviscerated body lying a few feet away. 
This intersection between the past and present in Candyman culminates at the climax of the film, in which Helen, who has escaped from a psychiatric ward and returned to Cabrini-Green, discovers a hook dangling from the ceiling and Candyman asleep on a slab of rock. She plunges the hook deep into his neck in an attempt to kill him, embracing Candyman's modus operandi. It doesn't work, however, and she surrenders herself to him in exchange for Anne-Marie's child, whom he kept alive. As she does this, Candyman says, "Our names will be written on a thousand walls, our crimes told and retold by our faithful believers. We shall die together in front of their very eyes and give them something to be haunted by" (1:22:20-1:22:37). Candyman then embraces Helen and kisses her with a mouth filled with bees, causing her to faint once again.

This scene, in which she is laid out on the slab of stone upon which Candyman had been lying and takes on the visual role of the sacrifice she has made of herself, also fits into Rose's technique of inverting traditional racial stereotypes to elicit fear from the audience and make them confront this within themselves. Here, Rose uses "[a trope] used much earlier in Birth of a Nation or King Kong: the ritual sacrifice of a virgin to a black potent male" (Hoeveler 99). While some, such as Diane Hoeveler, a professor at Marquette University, argue that Candyman simply replicates the stereotypes that they are supposedly speaking against, this scene in fact does the opposite. Helen's surrender to Candyman, rather than just playing into traditional tableaus of white fear about the corruption of white women by black men, represents Helen's acceptance of the raw power of the brutal history of repression that Candyman symbolizes and shows that she is willing to allow herself to be crushed by it if it means saving an innocent member of the next generation raised on the site of such atrocities.

When Helen awakes, she sees a mural depicting Candyman's former lover, who is an exact mirror image of her, and then hears the cries of a child, which draw her out of the building to a large pile of broken furniture that the residents of the building were planning to use for a bonfire that night. As she slips into the pile to find the source of the cries, the young boy that she had so recently consoled in the police station, Jake, sees her and whispers, "He's here" (1:26:23-1:26:24), before gathering the residents of Cabrini-Green and telling them to set fire to the pile of furniture because he saw Candyman go in there, which they do almost immediately.

In this scene, the fact that these people are so quick to light the fire exhibits their intense hatred of the figure they know as Candyman: the gang leader. It is people like him that have given Cabrini-Green such a deplorable and negative reputation, and, given the chance, they do not hesitate to set that image ablaze. The fierceness and ferocity with which they set fire to the furniture also echoes the lynching that happened there centuries ago, only this time it is the black 
residents of Cabrini-Green taking revenge against injustice rather than an injustice being intentionally committed.

Helen is able to save the baby, but she, along with the ghostly Candyman, perish in the flames. At Helen's funeral, a procession of the residents of Cabrini-Green walks through the graveyard in silence, and Jake, wearing a coat that looks like a much brighter and bloodless version of Candyman's, casts the very hook that Helen used to try to kill Candyman into her open grave. In this moment, Helen takes on the haunting mantle of Candyman for these people. The gang leader has been removed from the area, and the ghost of Daniel Robitaille was shown to be truly gone when the camera zoomed in on what looked like a charred corpse in the bonfire, so there is no one left that this role could be placed upon but her. The fact that this tableau cuts away immediately to Helen's funeral only compounds this transition, and her new identity is confirmed at the end of the movie. When Trevor says "Helen" five times in the bathroom mirror while grieving, she appears to him as she looked in death, the skin on her head burned and scarred, holding the hook that was cast into her grave. When Trevor's girlfriend, who he had been seeing secretly while married to Helen, opens the bathroom door, she finds him split open from his waist to his ribs and screams, standing over him holding a kitchen knife that she had been using to make dinner. The final shots of the movie then cut to and zoom in on a new mural in Cabrini-Green: Helen rising from the bonfire in a swirl of flame, her head surrounded in a fiery corona, looming above the terrified people below like a vengeful spirit or god.

By taking on the mantle of Candyman, Helen reversed the traditional perceptions of the history of racial violence in the United States. Instead of the original Candyman, who represented the idea of this racial violence being ignored as a serious presence by the white middle- and upper-class intellectuals of the university and yet instilling great fear in the hearts of the mainly African American residents of Cabrini-Green, the movie now has Helen, who, as a well-to-do white intellectual, is emblematic of the very people who have incited or tacitly perpetuated the racial violence that has plagued American history. Now, instead of hurting the people who have suffered from this abuse for so long, Helen is killing people like Trevor, the very individuals who denied the power of racial violence to haunt and inflict pain upon modern America and who, just one hundred years ago, may have personally murdered Daniel Robitaille.

There are some, however, who do not take the story beats of Candyman to be so self-aware and critical of traditional American attitudes toward history. Author Michael Blouin, for example, sees Candyman's interpretation of and attention to race as too generalizing and bland, saying, "When Candyman moves to diminish divisions between a black man and a white woman, casting 
these differences as 'merely superficial,' it willfully overlooks crucial distinctions between the material circumstances of these groups" (87). This is an understandable interpretation; however, the film not only acknowledges the difference in circumstances between Candyman and Helen but uses this gap deliberately to enhance the meaning of Helen's replacement of him. As an emblem of death and reversal of fortune to white intellectuals in the modern age, she will become a fearful tale to haunt the consciousnesses of people like Trevor, just as Candyman haunted the minds of the black residents of Cabrini-Green.

This haunting also forces the white intellectuals who will whisper Helen's name and spread her story to reckon with the fact that the homes they thought were so secure and separate from places like Cabrini-Green may no longer be so safe. Perhaps they never were. The mirror images and doubling that have been on display so explicitly throughout the film are exactly what allows this fear to manifest: they blur the lines between Helen and Candyman's roles as victim and monster and similarly blur the lines between the safety of white privilege and ignorance and the dirty realities of places like Cabrini-Green (Kee 52-53). Just like in Helen's apartment, which was only one shiny veneer away from being a housing project, the pervasive fear that the white middle and upper classes have of places suffering from urban decay has been turned on its head: it's not the projects where they can't feel safe anymore, but their own homes. The very people who would be so quick to deny that Candyman even existed will now be forced to reckon with the prejudices and histories that they have for so long ignored or risk ending up like Helen and becoming a whisper in the classroom, the writing on the wall. 


\section{Works Cited}

Abbot, Stacey. "Candyman and Saw: Reimagining the Slasher Film through Urban Gothic." Style and Form in the Hollywood Slasher Film, edited by Wickham Clayton, Palgrave Macmillan, 2015, pp. 67-78.

Austen, Ben. "Cabrini-Green and a horror film that captured the fears of public housing." Chicago Tribune, 16 Aug. 2018, https://www.chicagotribune.com/opinion/commentary/ct-perspecflashback-cabrini-green-candyman-public-housing-austen-0819-20180815-story.html Blouin, Michael J. "Candyman and Neoliberal Racism." Magical Thinking, Fantastic Film, and the Illusions of Neoliberalism, Palgrave MacMillan, 2016, pp. 81-108.

Briefel, Aviva and Sianne Ngai. "'How much did you pay for this place?' Fear, Entitlement, and Urban Space in Bernard Rose's Candyman." Camera Obscura, vol. 13, no. 1, 1996, pp. 69-91. https://doi.org/10.1215/02705346-13-1_37-69.

Candyman. Directed by Bernard Rose, TriStar Pictures, 1992.

Evans, Timothy H. "A Last Defense against the Dark: Folklore, Horror, and the Uses of Tradition in the works of H. P. Lovecraft." Journal of Folklore Research, vol. 42, no. 1, January-April 2005, pp. 99-135. JSTOR, https://www.jstor.org/stable/3814792.

Grant, Barry Keith. "Rich and Strange: The Yuppie Horror Film." Journal of Film and Video, vol. 48, no. 1/2, spring-summer 1996, pp. 4-16. JSTOR, https://www.jstor.org/stable/ 20688090.

Hoeveler, Diane. "The Postfeminist Filmic Female Gothic Detective: Reading the Bodily Text in Candyman." Postfeminist Gothic, edited by Benjamin A. Brabon and Stéphanie Genz, Palgrave Macmillan, 2007, pp. 91-113.

Kee, Jessica Baker. "Black Masculinities and Postmodern Horror: Race, Gender, and Abjection." Visual Culture and Gender, vol. 10, 2015, pp. 47-56.

Macek, Steve. "Places of Horror: Fincher's 'Seven' and Fear of the City in Recent Hollywood Film." College Literature, vol. 26, no. 1, winter 1999, pp. 80-97. JSTOR, https://www. jstor.org/stable/25112430.

Wyrick, Laura. "Summoning Candyman: The Cultural Production of History." Arizona Quarterly: A Journal of American Literature, Culture, and Theory, vol. 54, no. 3, autumn 1998, pp. 89-117. Project MUSE, doi:10.1315/arq.1998.0003. 